\title{
Perceived Hindrances Experienced by Sport Coaches in South Africa
}

\author{
by \\ Alliance Kubayi1,2, Yoga Coopoo ${ }^{1}$, Heather Morris-Eyton ${ }^{1}$
}

The purpose of this study was to examine perceived hindrances encountered by sport coaches in the Gauteng Province of South Africa. A total of 224 sport coaches (122 males and 102 females) were purposively recruited to participate in this study. An exploratory factor analysis was used to assess the factor structure of the Perceived Hindrance Scale. The results of this study indicated the following as major hindrances encountered by sport coaches: "Lack of support systems for women players", "Lack of support for women coaches from superiors", "Low salary", "Lack of opportunities for promotion", "Difficulties with parents/spectators" and "Lack of job security". Recommendations on strategies to overcome these perceived hindrances are discussed.

Key words: coaching, hindrances, occupation.

\section{Introduction}

Sport coaching is a highly visible occupation and the benefits associated with coaching make it an attractive profession (Wuest and Fisette, 2012). These benefits include the financial rewards, opportunity to work with athletes, prestige and recognition, satisfaction associated with giving the best of oneself, enjoyment, the social status achieved from coaching and the excitement of winning (Lyle et al., 1997; Surujlal and Nguyen, 2011; Wuest and Fisette, 2012). Although the benefits associated with coaching are well documented in literature, the Barriers Model of Occupational Choice postulates that individuals - in this case, coaches - may also experience numerous external obstacles or hindrances to their entry into the occupation (coaching) or subsequent satisfaction of their needs (Everhart and Chelladurai, 1998). These hindrances have been identified in the literature as including harassment, long working hours, burnout, homophobia, pressure to win, job insecurity, discrimination, lack of informal networking and social support (Demers, 2004; Everhart and Chelladurai, 1998; Kamphoff, 2010; Kerr and Marshall, 2007).

Another obstacle relates to family-work conflict. This conflict is more prevalent for female coaches than their male counterparts (Boloorizadeh et al., 2013). A plausible reason could be that women perform multiple roles, i.e. coach, wife, loco parentis, mother, and so forth. Kerr and Marshall (2007) further demonstrated that female coaches with children are more likely to experience the role conflict. For instance, Kamphoff (2010) revealed how one female coach left coaching because she could not give her children the time, attention, and energy they needed and deserved. This could be attributed to the fact that childcare is typically not provided during training, travel, and competition schedules (Kerr and Marshall, 2007). In fact, sport organisations view family responsibilities as being outside of their control and interest (Kerr and Marshall, 2007). Consequently, female coaches

1 - Department of Sport and Movement Studies, University of Johannesburg, South Africa.

2 - Department of Sport, Rehabilitation and Dental Sciences, Tshwane University of Technology, South Africa. 
have to juggle family and work demands simultaneously due to societal expectations (Eagly and Carli, 2007). As a result, the extraordinary amount of time and effort required to be effective as a coach could be seen as an obstacle to normal social life (Everhart and Chelladurai, 1998), thus resulting in female coaches jettisoning the coaching profession. Any factor that decreases the number of people entering the sport coaching profession is of great concern, particularly as the number of sport participants increases (Kerr and Ali, 2012).

Despite scientific literature being replete with overwhelming information on hindrances to sport coaching in other countries (Everhart and Chelladurai, 1998; Kamphoff, 2010; LaVoi and Dutove, 2012), very little is known about the impediments encountered by sport coaches in South Africa. Although inadequate resources, job insecurity, pressure from fans, media, and management have been reported as leading factors for the exodus from the coaching profession (Singh, 2001; Surujlal and Nguyen, 2009; Surujlal et al., 2004), these factors seem anecdotal as there is hardly any available study which has primarily examined the hindrances faced by sport coaches in South Africa. Thus, the present study attempted to fill the void in the literature as such information could help sport organisations to design strategies that could help to retain sport coaches in the country. Therefore, the present study was carried out to ascertain perceived hindrances experienced by sport coaches using exploratory factor analysis.

\section{Material and Methods}

\section{Participants}

A total of 224 sport coaches (122 males and 102 females) from the Gauteng Province of South Africa participated in this study. The participants represented a variety of sports: soccer $(n=87)$, athletics $(n=45)$, netball $(n=44)$, cricket $(n=19)$, rugby $(n=12)$, swimming $(n=10)$, boxing $(n=4)$; three coaches did not indicate their sports. Forty-five per cent of the coaches were in the 1825 years age group, $30 \%$ in the 26-35 years age group, $20 \%$ in the $36-45$ years age group, $4 \%$ in the 46-65 years age group and 1\% older than 65 years of age. Concerning employment status, $67 \%$ of the participants were volunteers, whereas 33\% were paid.

\section{Research instrument}

The Perceived Hindrance Scale (PHS) developed by Kamphoff and Gill (2008) was used to collect data. The questionnaire was comprised of 34 items measured on a 9-point Likert scale ranging from 1 (not at all a hindrance) to 9 (completely a hindrance). The instrument measures the following five subscales: minority/gender bias (e.g., "Racial/ethnic minority coaches are discriminated against", "Racial/ethnic minority coaches are treated unfairly"), gender issues (e.g., "Lack of support for women coaches from superiors", "Lack of support systems for women players"), nature of coaching (e.g., "Having to do a lot of training", "Unfavourable working hours"), conflicts with others (e.g., "Coaching interferes with social life", "Difficulties with parents/spectators") and professional issues (e.g., "Low salary", "Lack of job security"). Participants were asked to rate the most important hindrances in their coaching profession. A Cronbach alpha coefficient of 0.95 was obtained for the entire questionnaire in the current study. This alpha value was higher than the benchmark level of 0.70 recommended by Nunnally and Bernstein (1994).

\section{Procedures}

Prior to data collection, permission to carry out the study was granted by the Research Ethics Committee of the University of Johannesburg and the Gauteng Sports Council. The principal researcher and fieldworkers administered the questionnaire to the participants. Participants were informed through a cover letter that their participation would remain anonymous and their responses would be confidential. The participants were identified at different coaching courses and seminars. In most instances, the questionnaires were completed under the supervision of the principal researcher and the fieldworkers prior to, or after, the coaching courses/seminars. In some instances, participants completed the questionnaire in their own convenient time and returned it to the principal researcher and fieldworkers at a prearranged time.

\section{Statistical analysis}

Descriptive statistics (means, standard deviations, frequencies and percentages) were used to analyse the data. The Cronbach alpha was used to determine the internal consistency of the scale. In addition, an exploratory factor analysis 
using the principal component analysis (PCA) was also employed to examine the factor structure of the PHS. According to Pallant (2011), the PCA groups items into meaningful factors and reduces a large number of related variables to a more manageable number (Pallant, 2011). All statistical analyses were conducted using the Statistical Package for Social Sciences (SPSS) version 22.

\section{Results}

Prior to performing PCA, the suitability of data was assessed for factor analysis. The correlation matrix revealed the presence of coefficients of .3 and above. The Kaiser-MeyerOlkin (KMO) measure of sampling adequacy was .886, exceeding the recommended value of .60 (Kaiser, 1974), and the Bartlett's Test of Sphericity $\left(x^{2}=3845.612 ; d f=561 ; p<0.000\right)$ provided sufficient evidence that the data were suitable to proceed with factor analysis. A minimum eigenvalue of 1 guided the extraction of factors. Table 1 presents the factor analysis on the PHS to sport coaching.

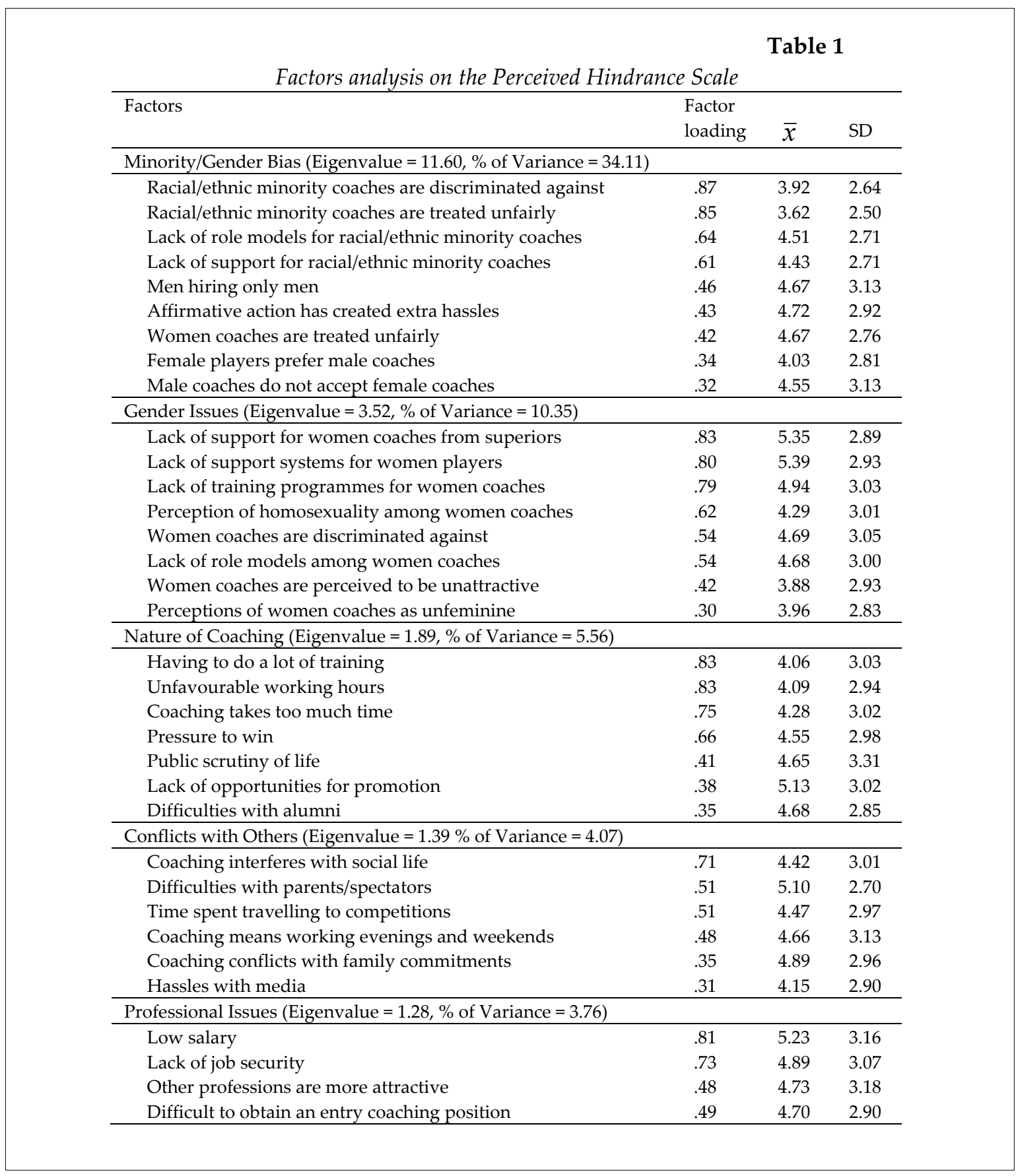


In terms of mean ranking, the major hindrances experienced by sport coaches were "Lack of support systems for women players" $(\mathrm{M}=5.39, \mathrm{SD}=2.93)$; "Lack of support for women coaches from superiors" $(\mathrm{M}=5.35, \mathrm{SD}=2.89)$; "Low salary" (M= 5.23, SD = 3.16); "Lack of opportunities for promotion" (M=5.13, $\mathrm{SD}=3.02)$; "Difficulties with parents/spectators" $(\mathrm{M}=5.10, \mathrm{SD}=2.70)$ and "Lack of job security" $(\mathrm{M}=4.98, \mathrm{SD}=3.07)$.

\section{Discussion}

This study examined hindrances experienced by sport coaches using a Kamphoff and Gill's (2008) scale. The results provide some evidence for the validity of the PHS based on principal component analysis and internal consistency testing of the subscales. The results further show that the overall scale had higher alpha value, demonstrating that the PHS is a reliable tool for assessing perceived hindrances to coaching in the South African context. Five factors, namely, minority/gender bias, gender issues, nature of coaching, conflicts with others and professional issues were identified through factor analysis. Factor 1, minority/gender bias, was comprised of 9 items and accounted for $34.11 \%$ of the variance. Factor 2, gender issues, consisted of 8 items and explained $10.35 \%$ of the variance. Factor 3 , nature of coaching, comprised 7 items which accounted for $5.56 \%$ of the variance. Factor 4 , conflicts with others, had 6 items and accounted for $4.07 \%$ of the variance and Factor 5, professional issues, consisted of 4 items accounting for $3.76 \%$ of the variance. The results of the PCA revealed the presence of the above five factors with Eigen values exceeding 1 , explaining a total of $57.85 \%$ of the variance. All five factors exceeded the recommended minimum of 0.30 which is considered as the benchmark for factor loadings (Hair et al., 2010). Consequently, all items were retained.

Overall, this study found the lack of support for women players and coaches to be major hindrances encountered by sport coaches. This finding is congruent with a study undertaken by Norman (2008) wherein it was reported that female coaches were isolated and not supported by their governing bodies. In her qualitative study, Norman (2008) further contended that one of the female coaches was overlooked for promotion although she was the most qualified woman coach in her sport.

Low salary was also reported as a major obstacle for sport coaches. This echoes the finding of Kamphoff (2010), who stated that meagre salaries had an impact on sport coaches' decisions to leave the coaching profession. The issue of such a salary amongst sport coaches in this study could be attributed to the fact that the majority of sport coaches $(44 \%)$ had no coaching qualifications, and previous research (Surujlal, 2004) had demonstrated that most of the sport federations in South Africa based their compensation systems on coaching qualifications and often favour qualified coaches. Therefore, this study recommends that sport coaches need to be encouraged to attend coaching courses so that they can earn a reasonable salary which might motivate them to stay in coaching for longer periods. Demers (2004) further argued that a good salary as an incentive would also motivate them to coach on a full-time basis. Although monetary incentives are important for the coach, other rewards which could motivate them to stay longer in coaching should also be introduced (Surujlal, 2006). These may include transport allowances and medical insurance.

Lack of opportunities for promotion was identified as another important setback to the sport coaches. A similar finding was reported by Kamphoff (2010), in whose study it was indicated that most of the sport coaches left the coaching profession for promotion opportunities in other professions. Therefore, this study suggests that a promotion system should be in place that could encourage such coaches to stay in their profession for longer periods. Sport coaches further indicated that they experienced difficulties with parents/spectators, probably because the majority of them were coaching children. This result is in agreement with that of Reade and Rodgers (2009), who found that dealing with parents, was a major challenge for sport coaches who coached young children.

Consistent with a view expressed by Reade and Rodgers (2009), the results of the present study demonstrate that sport coaches in South Africa are not given the necessary tools to deal with parents effectively. According to Weinberg and Gould (2007), negative behaviour in youth sport will never be completely 
eliminated; however, what can be done is to educate parents about their role in sport. This could be achieved by inviting parents to attend club meetings with a view to informing them about the team rules, the coach's philosophy, and the roles played by parents, coaches, and athletes (Weinberg and Gould, 2007). Informing parents about the responsibilities the coach expects them to fulfil should be the most important part of the meeting (Smoll et al., 2011), and this might prevent conflict between parents and coaches. More positively, the meeting might strengthen the coach-parent relationship, thus resulting in high levels of sport participation among children.

Another important hindrance which emerged from this study is the lack of job security. The literature indicates that there is a high turnover of sport coaches in South Africa, particularly in soccer and rugby (Surujlal, 2004). In order to enhance the job security of sport coaches, it is recommended that their contracts are equally binding for both the coaches and the sport clubs (Surujlal et al., 2004). This will afford security for both the coach and the sport club for a specific period of time. The suggestions that coaching interferes with social life, takes too much time and conflicts with family commitments were, however, not supported by the results of the present study. Our results contradict those of Kamphoff (2010), who found time constraints and family commitments to be major hindrances to sport coaching. These discrepancies could be explained in the light of the fact that most of the sport coaches $(71 \%)$ in the present study were single. Consequently, it is possible that since they were unmarried they might not have gained a firm grasp on future social and family commitments (Everhart and Chelladurai, 1998).
An unexpected finding in this study is that discrimination was perceived as the least hindrance in coaching. This finding is inconsistent with findings of a study conducted by Kamphoff (2010), who reported that most of the sport coaches were discriminated against; and, that, in some way, the homophobic atmosphere had an impact on the decision of lesbian coaches to leave coaching. A possible explanation for the observed finding could be that since the majority of sport coaches $(63 \%)$ were inexperienced, it is possible that they might have not yet experienced discrimination in their coaching careers. Another plausible explanation is that such coaches could have regarded discrimination as something that they could surmount in their future career (Everhart and Chelladurai, 1998).

\section{Conclusion}

The results of this study highlight the perceived hindrances encountered by sport coaches, which include lack of support for women coaches and players, inadequate salary, lack of opportunities for promotion, difficulties for working with parents/spectators and job insecurity. Based on the results of this study, the following recommendations are proffered. First, female coaches, who are role models, should be invited to discuss challenges facing female athletes and coaches, respectively, and how they can be addressed. Second, coach-parent meetings should be organised regularly by teams as this will minimise conflicts between coaches and parents, thus maximising children's participation in sports. Finally, a sport association for coaches should be formed. This will ensure equitable salaries and guarantee that the needs of the sport coaches are well catered for.

\section{Acknowledgements}

The financial assistance of the University of Johannesburg and CATHSSETA towards this study is gratefully acknowledged.

\section{References}

Boloorizadeh P, Tojari F, Zargar T. Work-family conflict among female head coaches in Iran. Procedia Soc Beh Sci, 2013; 84: 1403-1410

Demers G. Why female athletes decide to become coaches - or not. Can J Women Coach, 2004; 4(5)

Eagly AH, Carli LL. Through the Labyrinth: The Truth About how Women Become Leaders. Boston, MA: Harvard Business School Press; 2007 
Everhart CB, Chelladurai P. Gender differences in preferences for coaching as an occupation: The role of selfefficacy, valence, and perceived barriers. Res Q Exerc Sport, 1998; 69(2): 188-200

Hair JF, Black B, Babin B, Anderson RE, Tatham RL, Black WC. Multivariate Data Analysis: A Global Perspective. NY: Pearson Education Inc; 2010

Hennink M, Hutter I, Bailey A. Qualitative Research Methods. London: Sage publications; 2011

Kaiser HF. An index of factorial simplicity. Psychometrika, 1974; 39: 31-36

Kamphoff CS. Bargaining with patriarchy. Res Q Exerc Sport, 2010; 81(3): 360-372

Kamphoff C, Gill D. Collegiate athletes' perceptions of the coaching profession. Int J Sport Sci Coach, 2008; 3(1): 55-72

Kerr G, Ali B. Perceived barriers to achieving gender equity in Canadian interuniversity sport: Perspectives of athletic directors. Can J Women Coach, 2012; 12(2)

Kerr G, Marshall D. Shifting the culture: Implications for female coaches. Can J Women Coach 2007; 7(4)

LaVoi NM, Dutove JK. Barriers and supports for female coaches: An ecological model. Sport Coach Rev, 2012; 1(1): 17-37

Lyle J, Allison M, Taylor J. Factors Influencing the Motivations of Sports Coaches. (Research Report no. 49) Edinburgh: Scottish Sports Council; 1997

Norman L. The UK coaching system is failing women coaches. Int J Sport Sci Coach, 2008; 3(4): 447-464

Nunnally JC, Bernstein IH. Psychometric Theory (3rd ed.). New York: McGraw-Hill; 1994

Pallant JF. SPSS Survival Manual: A Step by Step Guide to Data Analysis Using SPSS (4th ed.). Crows Nest, NSW: Allen \& Unwin; 2011

Reade I, Rodgers W. Common coaching challenges and their association with coach and contextual characteristics. J Coach Educ, 2009; 2(2): 1-24

Singh PC. The job security of coaches. SA J Res Sport Phys Educ Recrea, 2001; 23(1): 65-73

Smoll FL, Cumming SP, Smith RE. Enhancing coach-parent relationship in youth sports: Increasing harmony and minimizing hassle. Int J Sport Sci Coach, 2011; 6 (1): 13-23

Surujlal J. Human Resources Management of Professional Sports Coaches. Unpublished PhD Thesis. Rand Afrikaans University, Johannesburg; 2004

Surujlal J. Compensation of professional sport coaches in South Africa. Afri J Phys Health Educ Recreat Dance, 2006; 12(1): 1-14

Surujlal J, Nguyen S. Sources of stressors in South African soccer coaches. Afri J Phys Health Educ Recreat Dance, 2009; September (Suppl 1): 113-124

Surujlal J, Nguyen S. Motives influencing soccer coaching: An empirical study of professional soccer coaches in South Africa. Afri J Phys Health Educ Recreat Dance, 2011; September (Suppl 1): $286-296$

Surujlal J, Singh PC, Hollander WJ. A comprehensive analysis of the job security of professional sports coaches in South Africa. SA J Res Sport Phys Educ Recrea, 2004; 26(2): 105-116

Weinberg RS, Gould D. Foundation of Sport and Exercise Psychology (4th ed.). Champaign, IL: Human Kinetics; 2007

Wuest DA, Fisette J. Foundation of Physical Education, Exercise Science and Sport (17 ${ }^{\text {th }}$ ed.). New York: McGrawHill; 2012

\section{Corresponding author:}

\section{Alliance Kubayi}

Tshwane University of Technology

Department of Sport, Rehabilitation and Dental Sciences, Republic of South Africa, Pretoria, 0001

Phone number: +27 123824272

Fax number: +27 123825801

E-mail address: kubayina@tut.ac.za 